\title{
Mechanistic Insights into Polar Monomer Insertion Polymerization from Acrylamides
}

\author{
Tobias Friedberger, Philipp Wucher, and Stefan Mecking* \\ Chair of Chemical Materials Science, Department of Chemistry, University of Konstanz, Universitätsstrasse 10, 78457 Konstanz, \\ Germany
}

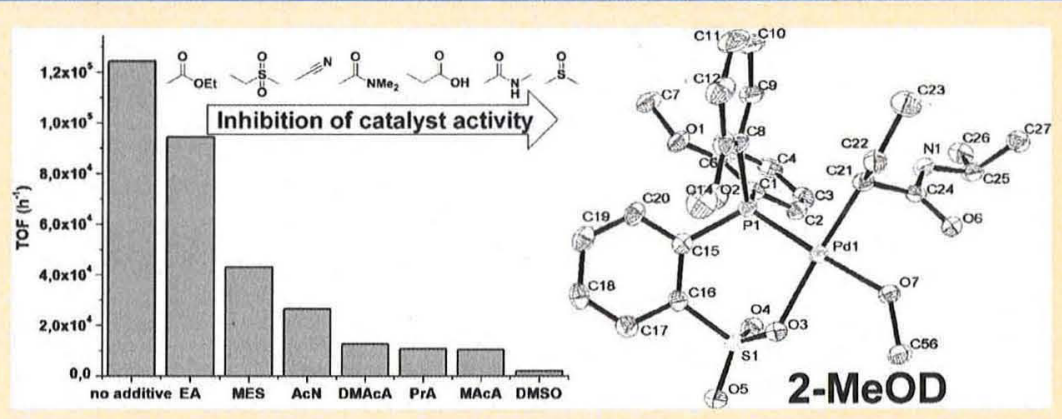

ABSTRACT: $N$-Isopropyl acrylamide (NIPAM), $N, N$-dimethyl acrylamide (DMAA), and 2-acetamidoethyl acrylate (AcAMEA) were copolymerized with ethylene employing [( $\left.\left.\mathrm{P}^{\wedge} \mathrm{O}\right) \mathrm{PdMe}(\mathrm{DMSO})\right]\left(1-\mathrm{DMSO}\right.$; $\mathrm{P}^{\wedge} \mathrm{O}=\kappa^{2}-\mathrm{P}, \mathrm{O}-\mathrm{Ar}_{2} \mathrm{PC}_{6} \mathrm{H}_{4} \mathrm{SO}_{2} \mathrm{O}$ with $\mathrm{Ar}=2$ $\left.\mathrm{MeOC}_{6} \mathrm{H}_{4}\right)$ as a catalyst precursor. Inhibition studies with nonpolymerizable polar additives show that reversible $\kappa$ - $O$ coordination of free amide retards polymerization significantly. Retardation of polymerization increases in the order ethyl acetate $\ll$ methyl ethyl sulfone < acetonitrile $<N, N$-dimethylacetamide $\approx N$-methylacetamide $\approx$ propionic acid $<$ dimethylsulfoxide. Pseudo-first-order rate constants for the insertion into 1-DMSO were determined to increase in the order DMAA $<$ AcAMEA < NIPAM < methyl acrylate. Exposure of 1-DMSO to NIPAM resulted in the formation of consecutive insertion products $\left[\left(\mathrm{P}^{\wedge} \mathrm{O}\right) \mathrm{Pd}\left(\mathrm{C}_{6} \mathrm{H}_{11} \mathrm{NO}_{2}\right)_{n} \mathrm{Me}\right](n \leq 3)$, as determined by electrospray ionization mass spectrometry. The solid-state structure of the methanol adduct of the 2,1-insertion product of NIPAM into 1-DMSO, [(P^O)Pd $\left\{\eta^{1}-\mathrm{CH}(\mathrm{CONHiPr}) \mathrm{CH}_{2} \mathrm{CH}_{3}\right\}\left(\kappa^{1}-O\right.$ $\mathrm{MeOD})]$ (2-MeOD), was determined by single crystal X-ray diffraction. Both 2,1-and 1,2-insertions of DMAA into the Pd-Me bond of a $\left[\left(\mathrm{P}^{\wedge} \mathrm{O}\right) \mathrm{PdMe}\right]$ fragment occur to afford a ca. 4:1 mixture of chelates $\left[(\mathrm{P} \wedge \mathrm{O}) \mathrm{Pd}\left\{\kappa^{2}-\mathrm{C}, \mathrm{O}-\mathrm{C}\left(\mathrm{CH}_{2} \mathrm{CH}_{3}\right) \mathrm{C}(\mathrm{O}) \mathrm{NMe}_{2}\right\}\right]$ (3) and $\left[\left(\mathrm{P}^{\wedge} \mathrm{O}\right) \mathrm{Pd}\left\{\kappa^{2}-\mathrm{C}, \mathrm{O}-\mathrm{CH}_{2} \mathrm{C}\left(\mathrm{CH}_{3}\right) \mathrm{C}(\mathrm{O}) \mathrm{NMe}_{2}\right\}\right]$ (4). The four-membered chelate of 3 is opened by coordination of 2,6lutidine $(3+2,6$-lutidine $\rightleftharpoons 3$-LUT $)$ with $\Delta H^{\circ}=-41.8(10.5) \mathrm{kJ}$ and $\Delta S^{\circ}=-115(37) \mathrm{J} \mathrm{mol}^{-1} \mathrm{~K}^{-1}$.

\section{INTRODUCTION}

Catalytic insertion polymerization of ethylene and propylene is one of the most well-studied chemical reactions. In terms of applications, it is employed for the production of more than 70 million tons of polyolefins annually. ${ }^{1}$ An insertion (co)polymerization of electron-deficient polar-substituted vinyl monomers like acrylates has remained a challenge, however.

Considerable progress in this area has been achieved by the development of $\mathrm{d}^{8}$-metal (late transition metal) complexes. Their less oxophilic nature, in comparison with their early transition metal counterparts, renders them more tolerant toward polar moieties. ${ }^{2}$ In the mid 1990s, cationic Pd(II) $\alpha$ diimine complexes were reported to catalyze the insertion copolymerization of ethylene and 1-olefins with acrylates. Because of the "chain walking" of the catalyst, the highly branched copolymers contain acrylate units preferentially at the end of branches. The mechanism of this branch formation is well understood from extensive variable temperature NMR studies. ${ }^{3}$ Such studies have also provided an understanding of the problems associated with monomers not amenable to polymerization with these catalysts, like vinyl acetate or vinyl chloride. $\beta$-X elimination ( $\mathrm{X}=$ acetate, chloride) is one significant decomposition route. ${ }^{4,22}$ In contrast, with neutral Pd(II) phosphinesulfonato complexes, linear copolymers of ethylene with a broad scope of polar vinyl monomers including acrylonitrile, vinyl acetate, and acrylic acid are formed. ${ }^{2 \mathrm{~h}, 5-7}$ These catalysts have been studied as in situ mixtures of $\mathrm{Pd}^{\mathrm{II}}$ or $\mathrm{Pd}^{0}$ sources and ligands ${ }^{8}$ and employing $\left[\left(\mathrm{P}^{\wedge} \mathrm{O}\right) \mathrm{PdMe}(\mathrm{L})\right](\mathrm{L}$ $=$ pyridine, 2,6-lutidine, $\mathrm{PPh}_{3}, 1 / 2 \mathrm{Me}_{2} \mathrm{NCH}_{2} \mathrm{CH}_{2} \mathrm{NMe}_{2}$, dimethylsulfoxide) complexes as well-defined single-component catalyst precursors. ${ }^{9}$ Recent experimental and theoretical mechanistic studies on the key intermediates of the insertion (co)polymerization of acrylates, $\kappa^{2}-\mathrm{C}, \mathrm{O}$-coordinated $\mathrm{Pd}(\mathrm{II})$ alkyl species $\left[\left(\mathrm{P}^{\wedge} \mathrm{O}\right) \mathrm{Pd}\left\{\kappa^{2}-\mathrm{CH}(\mathrm{C}(\mathrm{O}) \mathrm{OMe}) \mathrm{CH}_{2} \mathrm{CH}(\mathrm{C}(\mathrm{O})\right.\right.$ $\left.\mathrm{OMe}) \mathrm{CH}_{2} \mathrm{CH}_{3}\right\}$ ], resulting from two consecutive 2,1-insertions of MA, showed that the chelating $\kappa$-O-coordination of the 
Table 1. Copolymerization with Ethylene ${ }^{a}$

\begin{tabular}{|c|c|c|c|c|c|c|c|c|c|c|}
\hline entry & comon. & $\mathrm{T}\left[{ }^{\circ} \mathrm{C}\right]$ & $\mathrm{p}[\mathrm{bar}]$ & comon. conc. $\left[\mathrm{mol} \mathrm{L}^{-1}\right]$ & polymer yield $[\mathrm{g}]$ & TOF $^{b} \mathrm{C}_{2} \mathrm{H}_{4}$ & $\mathrm{TOF}^{b}$ comon. & $\mathrm{X}_{\mathrm{A \Lambda}} c^{c, d}$ & $M_{\mathrm{n}}{ }^{e}\left[10^{3} \mathrm{~g} \mathrm{~mol}^{-1}\right]$ & $M_{\mathrm{w}} / M_{\mathrm{n}}{ }^{\mathrm{C}}$ \\
\hline $1-1$ & NIPAM & 80 & 20 & 0.2 & 0.365 & 619 & 3 & 1.7 & 5.8 & 2.0 \\
\hline $1-2$ & NIPAM & 80 & 20 & 0.5 & 0.110 & 183 & 1 & 2.4 & 3.4 & 2.0 \\
\hline $1-3$ & NIPAM & 80 & 20 & 1.0 & 0.044 & 72 & 1 & 3.1 & 2.4 & 1.7 \\
\hline $1-4$ & DMAA & 80 & 20 & 0.2 & 1.085 & 1922 & 3 & 0.6 & 9.6 & 2.0 \\
\hline $1-5$ & DMAA & 95 & 20 & 0.2 & 1.402 & 2482 & 5 & 0.7 & 6.8 & 2.1 \\
\hline $1-6$ & DMAA & 95 & 10 & 0.2 & 0.568 & 1000 & 3 & 1.2 & 4.3 & 2.2 \\
\hline $1-7$ & DMAA & 93 & $s$ & 0.2 & 0.260 & 456 & 2 & 1.7 & 3.1 & 2.1 \\
\hline $1-8$ & DMAA & 90 & $s$ & 1.0 & 0.051 & 88 & 1 & 3.6 & 1.2 & 1.5 \\
\hline $1-9$ & DMAA & 90 & 20 & 2.2 & 0.042 & 72 & 1 & 3.5 & 1.5 & 1.6 \\
\hline $1-10^{f}$ & AcAMEA & 95 & 5 & 0.2 & 0.160 & 266 & 4 & 6.9 & 0.7 & 1.4 \\
\hline
\end{tabular}

${ }^{a}$ Reaction conditions: $20 \mu \mathrm{mol}$ 1-DMSO; total volume toluene + comonomer, $50 \mathrm{~mL}$; polymerization time, $1 \mathrm{~h} .{ }^{b}$ TOF in mol(monomer incorporated) $\mathrm{mol}$ (catalyst) ${ }^{-1} \mathrm{~h}^{-1}$. ${ }^{c} \mathrm{Molar}$ incorporation in copolymer. ${ }^{d} \mathrm{From}{ }^{1} \mathrm{H} \mathrm{NMR}$ in $\mathrm{C}_{2} \mathrm{D}_{2} \mathrm{Cl}_{4}$ at $130{ }^{\circ} \mathrm{C}$. ${ }^{e} \mathrm{From} \mathrm{GPC}$ at $160{ }^{\circ} \mathrm{C}$ in $1,2,4-$ trichlorobenzene vs linear polyethylene. ${ }^{f}$ Micro size reactor with $5 \mathrm{~mL}$ total reaction volume of the liquid phase.

Scheme 1. Copolymerization of Amide Comonomers with Ethylene ( $U=$ Unsaturated and $S=$ Saturated Chain End)
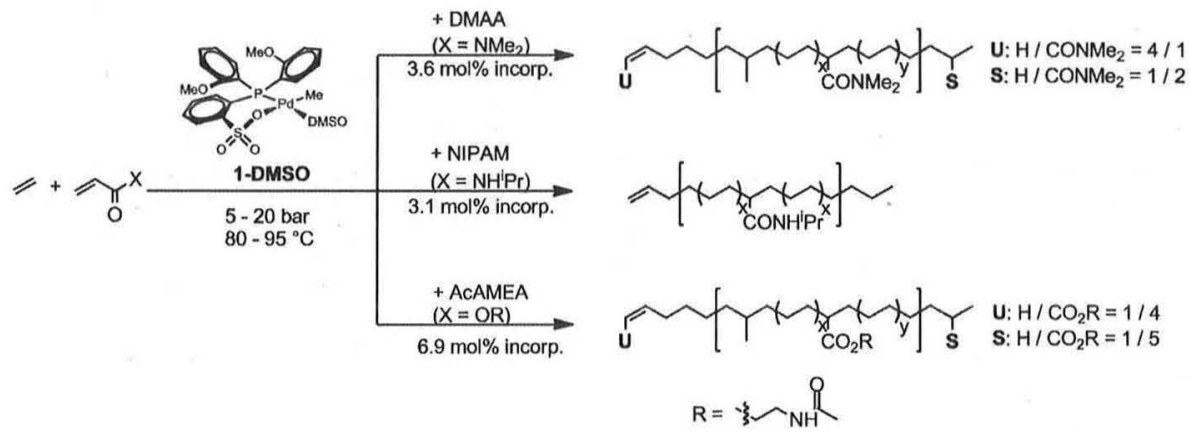

second last inserted acrylate unit significantly retards further chain growth. ${ }^{10,11}$

Materials containing amide moieties are of general interest due to the exceptional hydrogen-bonding ability of amides, which can be reflected in specific properties and structures. However, reports of amide-containing (co)polymers obtained by insertion polymerization are rare. The copolymerization of acrylamides passivated with aluminum alkyls by $\alpha$-diimine $\mathrm{Ni}$ (II) complexes was reported to yield copolymers with low acrylamide contents $(<5 \mathrm{~mol} \%){ }^{12}$ Claverie et al. communicated the preparation of linear ethylene- $\mathrm{N}, \mathrm{N}$-isopropylacrylamide (NIPAM) and ethylene- $\mathrm{N}$-vinyl-2-pyrrolidone copolymers with $\mathrm{Pd}(\mathrm{II})$ phosphinesulfonato complexes $\left[\left(\mathrm{P}^{\wedge} \mathrm{O}\right) \mathrm{PdMe}-\right.$ (pyridine)] as catalyst precursors. ${ }^{6 \mathrm{~d}, 13}$ An exclusive in-chain incorporation of NIPAM was observed, and no NIPAM-derived chain ends were detected. Beyond these findings, no comprehensive picture of the properties of amides in insertion polymerizations and a mechanistic understanding exist. We now give a full account of the reactivity of acrylamides in insertion (co)polymerizations catalyzed by neutral phosphinesulfonato $\mathrm{Pd}(\mathrm{II})$ complexes and rationalizations on polar monomer insertion polymerization in general from the insights gained.

\section{RESULTS AND DISCUSSION}

Copolymerization Studies and Copolymer Microstructure. The copolymerization of ethylene with the tertiary amide dimethylacrylamide (DMAA), and for comparison also with NIPAM, was studied (Table 1 and Scheme 1). As a catalyst precursor, the DMSO-coordinated complex $\left[\left(\mathrm{P}^{\wedge} \mathrm{O}\right)\right.$ $\mathrm{PdMe}(\mathrm{DMSO})]$ ( $\mathrm{P}^{\wedge} \mathrm{O}=2$-[di(2-methoxyphenyl)phosphino $]$ -

benzenesulfonate) (1-DMSO) was employed. Because of the relatively weak binding of DMSO by comparison to other stabilizing ligands, such as pyridine, polymerizations can be performed with reasonable activities also at low ethylene pressure and thus at high [comonomer] $/[$ ethylene $]$ ratios. ${ }^{9 \mathrm{e}}$ At a relatively high $[$ DMAA $] /[$ ethylene $]$ ratio $([D M A A]=1 \mathrm{~mol}$ $\mathrm{L}^{-1}$ and $\mathrm{p}$ (ethylene) $=5 \mathrm{~atm}$; entry 1-8), an incorporation of the tertiary amide of $3.6 \mathrm{~mol} \%$ was observed. As expected, at a given ethylene pressure, the incorporation of amide in the polymer increases with the concentration of acrylamide monomer in the reaction mixture (entries 1-5 vs 1-9 and 1-7 vs 1-8). At the same time, productivity decreases significantly. Likewise, at a given acrylamide concentration, the ethylene content of the copolymers increases with ethylene concentration, and notably productivity also increases (entries 1-5 to 1-7). These findings already indicate that amide functions retard the polymerization reaction. The catalyst was stable over the time of the reaction and showed single site behavior as concluded from molecular weight distributions $M_{\mathrm{w}} / M_{\mathrm{n}}$ around 2. A comparison of the copolymer compositions formed under identical reaction conditions, and of the reaction conditions under which copolymers of similar degree of incorporation of amide are formed, shows that DMAA competes less efficiently with ethylene incorporation than NIPAM.

By comparison to previous studies of ethylene-methyl acrylate (MA) copolymerization, the activities and incorporations in the copolymerizations of amides (cf. Table 1) are lower. Under otherwise similar conditions ( 5 atm ethylene, [MA] $=0.6 \mathrm{~mol} \mathrm{~L}^{-1}, 95{ }^{\circ} \mathrm{C}$ ), 1-DMSO yielded $2.57 \mathrm{~g}$ of an ethylene-MA copolymer with $9.4 \mathrm{~mol} \%$ MA content. ${ }^{9 \mathrm{e}}$ To shed light on the origin of this different behavior, 
copolymerizations of 2-acetamidoethyl acrylate (AcAMEA) (entry 1-10) were studied. Whereas the copolymer was obtained in a comparably low yield of $0.15 \mathrm{~g}$, the incorporation rate of $6.9 \mathrm{~mol} \%$ AcAMEA was about two times higher than in the ethylene-acrylamide copolymerizations. As expected, these incorporations are more similar to MA incorporation, and the lower incorporation of AcAMEA vs MA can be rationalized by the higher steric bulk of the former, which disfavors coordination vs the ethylene comonomer. The lower yield suggests that amide moieties in the monomer in general, also in a remote position, hinder the polymerization reaction (vide infra).

High-temperature NMR spectroscopy (see the Supporting Information) unambiguously confirmed the copolymer nature of the materials. The composition of the end groups was of particular interest as the reported ethylene-NIPAM and -NVP copolymers did not show end groups derived from polar monomer, ${ }^{6 \mathrm{~d}}$ which differs from copolymers of ethylene and other electron-withdrawing substituted polar vinyl monomers obtained with $\mathrm{Pd}(\mathrm{II})$-phosphinesulfonato complexes where usually the majority of end groups are based on the polar vinyl monomer. The ethylene-NIPAM copolymers obtained here with 1-DMSO (entries 1-1 to 1-3) possessed no observable NIPAM-derived end groups, in accordance with previous findings by Claverie et al. ${ }^{6 \mathrm{~d}}$ In the ethylene-DMAA copolymer with $3.5 \mathrm{~mol} \%$ incorporation (entry 1-9), DMAAbased repeat units were found to be incorporated in-chain, in saturated, and in unsaturated chain-ends in a ratio of $6: 3: 1$. The ratio of saturated ethylene- and DMAA-derived end groups was found to be $1: 2$, which roughly reflects the concentration of the monomers ${ }^{14}$ in the reaction mixture; that is, there is no strong preference for one of the monomers regarding insertion into a $\mathrm{Pd}-\mathrm{H}$ bond. This differs from chain growth by insertion into alkyls, in which ethylene is preferred over the polar monomer (Scheme 1). Accordingly, no saturated end groups resulting from an insertion of DMAA and AcAMEA into the Pd-Me bond of 1-DMSO were observed. In the unsaturated end groups, ethylene-derived groups prevail by ca. $4: 1$. Considering that the incorporation ratio of ethylene vs DMAA in the polymer backbone is ca. 30 , this indicates that $\beta$ - $\mathrm{H}$ elimination occurs preferentially from the insertion product of the acrylamide polar monomer. ${ }^{15}$ Even for a copolymer with a low DMAA incorporation formed at 20 bar ethylene (entry 14) the amide-derived end groups were observable (ethylene- vs amide-derived 1:12). With regard to the regiochemistry of the insertion, both DMAA- and AcAMEA-derived unsaturated end groups observed originate from a 2,1-insertion product exclusively.

The ethylene-AcAMEA copolymer with $6.9 \mathrm{~mol} \%$ incorporation predominantly possesses acrylate over ethylenederived end groups both in the saturated and unsaturated end groups ( $80 \%$ acrylate-derived unsaturated end groups, $85 \%$ saturated end groups). An analogous pattern of end groups was found previously for ethylene-MA copolymers. ${ }^{\text {ee }}$ This suggests that the pendant amide moiety of AcAMEA has no strong influence on the microstructure of the copolymers, as expected. In summary, $\beta$-hydride elimination after an acrylamide insertion occurs less readily than in the case of acrylates, which is distinctively reflected in the end group pattern.

Inhibition of Polymerization by Amides. The limited polymerization activities of 1-DMSO in the presence of amidecontaining monomer raise the question of the nature of interactions with the metal centers. When a small excess $(3-5$ equiv) of a nonpolymerizable saturated amide, $N$-methyl acetamide (MAcA) or $\mathrm{N}, \mathrm{N}$-dimethyl acetamide (DMAcA), respectively, was added to an NMR tube charged with 1DMSO in methylene chloride- $d_{2}$ at room temperature, fast exchange of coordinated DMSO and amide was observed. The corresponding highfield-shifted proton resonance of DMSO $(\delta$ $=2.65$ and $2.70 \mathrm{ppm}$, respectively) did not correspond to bound $(\delta=2.91 \mathrm{ppm})$ or free $(\delta=2.54 \mathrm{ppm})$ DMSO (Figures S8 and S9, Supporting Information). No further reaction with the acetamides was observed, even after warming the samples to $60^{\circ} \mathrm{C}$ for $90 \mathrm{~min}$. This stability of the catalyst precursor in the presence of amides at elevated temperature is in agreement with ethylene homopolymerization data in the presence of DMAcA (Table S1, Supporting Information). Average activities determined from the polymer yields in 15 and $60 \mathrm{~min}$ polymerization experiments are similar; in detail, the activity is lower by one-fifth in the one hour experiment. A similar decrease in activity over time was also found in homopolymerizations of ethylene in the absence of any polar additives. ${ }^{68}$ Catalyst activities in ethylene homopolymerizations employing 1-DMSO decreased with increasing acetamide concentration in the polymerization mixture (Table 2). Compared with a

Table 2. Homopolymerizations of Ethylene in the Presence of Polar Additives ${ }^{a}$

\begin{tabular}{|c|c|c|c|c|c|c|}
\hline entry & additive & $\begin{array}{c}\text { additive } \\
\text { conc. } \\
{\left[\mathrm{mol} \mathrm{L}^{-1}\right]}\end{array}$ & $\begin{array}{l}\text { polymer } \\
\text { yield }[\mathrm{g}]\end{array}$ & $\begin{array}{c}\text { average } \\
\text { TOF } \\
{\left[10^{3} \mathrm{~h}^{-1}\right]}\end{array}$ & $\begin{array}{c}M_{\mathrm{n}}{ }^{c} \\
{\left[10^{3}\right.} \\
\left.\mathrm{g} \mathrm{mol}^{-1}\right]\end{array}$ & $\begin{array}{l}M_{w} / \\
M_{n}{ }^{c}\end{array}$ \\
\hline $2-1$ & & & 4.357 & 124.3 & 17.0 & 2.0 \\
\hline $2-2$ & MAcA & 0.002 & 3.683 & 105.0 & 17.0 & 1.9 \\
\hline $2-3$ & MAcA & 0.05 & 0.366 & 10.4 & 10.8 & 2.1 \\
\hline $2-4$ & MAcA & 0.10 & 0.169 & 4.8 & 9.8 & 2.0 \\
\hline $2-5$ & MAcA & 0.20 & 0.088 & 2.5 & 10.7 & 1.8 \\
\hline $2-6$ & DMAcA & 0.004 & 2.326 & 66.3 & 18.2 & 1.9 \\
\hline $2-7$ & DMAcA & 0.05 & 0.442 & 12.6 & 9.7 & 2.4 \\
\hline $2-8$ & DMAcA & 0.10 & 0.238 & 6.8 & 15.6 & 1.8 \\
\hline $2-9$ & DMAcA & 0.20 & 0.141 & 4.0 & 6.7 & 2.2 \\
\hline $2-10$ & EA & 0.05 & 3.308 & 94.3 & 12.1 & 2.1 \\
\hline $2-11$ & EA & 0.10 & 1.722 & 49.2 & n.d. & n.d. \\
\hline $2-12$ & DMSO & 0.05 & 0.062 & 1.8 & 1.1 & 1.7 \\
\hline $2-13$ & $\mathrm{AcN}$ & 0.05 & 0.926 & 26.4 & n.d. & n.d. \\
\hline $2-14$ & $\mathrm{AcN}$ & 0.10 & 0.678 & 19.4 & n.d. & n.d. \\
\hline $2-15$ & $\mathrm{AcN}$ & 0.30 & 0.291 & 8.3 & n.d. & n.d. \\
\hline $2-16$ & MES & 0.05 & 1.506 & 43.0 & n.d. & n.d. \\
\hline $2-17$ & MES & 0.10 & 1.354 & 38.7 & n.d. & n.d. \\
\hline $2-18$ & $\operatorname{Pr} A$ & 0.05 & 0.376 & 10.7 & n.d. & n.d. \\
\hline $2-19$ & PrA & 0.10 & 0.310 & 8.8 & n.d. & n.d. \\
\hline
\end{tabular}

${ }^{a}$ Reaction conditions: $2.5 \mu \mathrm{mol}$ 1-DMSO, $10 \mathrm{bar}, 80^{\circ} \mathrm{C}, 30 \mathrm{~min}$, total volume toluene + additive $50 \mathrm{~mL}$. ${ }^{b} \mathrm{TOF}$ in $\mathrm{mol}(\mathrm{PE}) \mathrm{mol}\left(\right.$ catalyst $^{-1}$ $\mathrm{h}^{-1}$. ${ }^{c}$ From GPC at $160^{\circ} \mathrm{C}$ in $1,2,4$-trichlorobenzene.

polymerization experiment in the absence of additives (entry 21), a 50-fold (MAcA, entry 2-5) and 30-fold (DMAcA, entry 29) lowered activity were observed with acetamide concentrations of $0.2 \mathrm{M}$. Note that this concentration corresponds to the minimum comonomer concentration applied for the copolymerizations (Table 1). For all acetamide concentrations, MAcA showed a slightly stronger inhibition than DMAcA. This can be related to a stronger coordination of secondary vs tertiary amide, likely due to the steric bulk of the latter. ${ }^{16}$ This difference in coordination strength may likewise contribute to the higher ethylene pressures required for the NIPAM copolymerizations in comparison with DMAA. 
In order to relate the inhibition by amides with other relevant functional groups present in vinyl monomers (or in the labile ligand of the catalyst precursors), ethylene homopolymerizations in the presence of $0.05 \mathrm{M}$ and higher concentrations of various saturated polar-substituted compounds were studied (Table 2 and Figure 1). DMSO (entry 2-12) inhibits

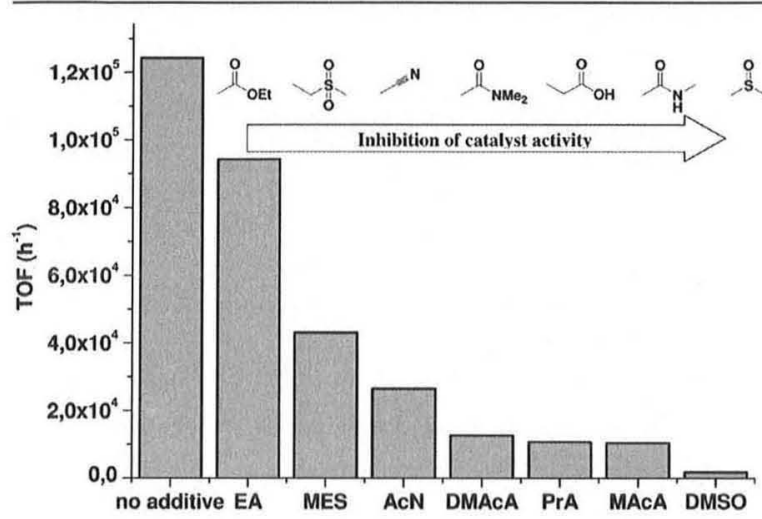

Figure 1. Inhibition of ethylene polymerization by saturated compounds with various polar groups (reaction conditions: 2.5 $\mu \mathrm{mol} 1$-DMSO, $10 \mathrm{bar}, 80^{\circ} \mathrm{C}, 30 \mathrm{~min}$, total volume of toluene and polar compound $50 \mathrm{~mL}, 0.05 \mathrm{M}$ of additive).

polymerization to a slightly larger extent than the amides MAcA and DMAcA, which is in agreement with the aforementioned ${ }^{1} \mathrm{H}$ NMR study. Ethyl acetate (EA, entries 210) exhibits a much lower effect on polymerization by comparison to all other compounds studied. Thus, the much higher polymerization rates in ethylene-acrylate copolymerization vs copolymerization of unsaturated amides can be traced to an inhibition of polymerization by coordination of the amide groups of the free monomer. The inhibition of ethylene polymerization observed for acetonitrile $(\mathrm{AcN})$, methyl ethyl sulfone (MES), and propionic acid (PrA) is in qualitative agreement with previous studies of the corresponding vinyl monomers. $^{6 \mathrm{~b}, \mathrm{f}, \mathrm{h}, 17}$ In this overall scheme, amides inhibit relatively strongly, similar to the carboxylic acid and stronger than the nitrile and the sulfone. For the oxygen-containing monomers, the impact on polymerization can be rationalized by the electronegativity of the oxygen-bound fragments $\mathrm{O}=\mathrm{X}$ and corresponding expected $\kappa$-O-binding strength to the electrophilic metal center (with the exception of the carboxylic acid, which does not follow this trend, possibly because of coordination in its deprotonated form).

Compared to ethylene homopolymerization in the presence of the saturated amide DMAcA (Table S2, Figure S10, Supporting Information), in copolymerization of DMAA (entries 1-5 to 1-7), activities are ca. 5-fold lowered. This suggests that also coordination of functional groups of incorporated monomer (vide infra) and slower insertion into electron-withdrawing substituted $\mathrm{Pd}$-alkyls formed after an insertion of polar comonomer by comparison to the unsubstituted alkyls from ethylene insertion affect copolymerization rates, as observed previously for other monomers. ${ }^{10}$

The binding strength of the ligand on the fourth coordination site of the phosphinesulfonato $\mathrm{Pd}(\mathrm{II})$ methyl catalyst precursor is decisive for its properties in (co). polymerization reactions. To this end, the relative binding of DMSO vs polar additives was investigated by ${ }^{1} \mathrm{H}$ NMR spectroscopy. The equilibrium (1-DMSO $+\mathrm{L} \rightleftarrows$ 1-L + DMSO) is fast on the NMR time scale at room temperature; only one DMSO signal (average of 1-DMSO and free DMSO) is observed upon addition of variable amounts of polar additives to a ca. $40 \mathrm{mM} \mathrm{CD} \mathrm{Cl}_{2}$ solution of 1-DMSO (Supporting Information Figure S11, Table S3). The estimated equilibrium constants $K_{\mathrm{eq}}(\mathrm{EA})<10^{-2}, K_{\mathrm{eq}}(\mathrm{MES})<10^{-2}, K_{\mathrm{eq}}(\mathrm{AcN}) \approx 1$, $K_{\text {eq }}(\mathrm{DMAcA}) \approx 0.4, K_{\mathrm{eq}}(\operatorname{PrA})<0.1, K_{\mathrm{eq}}(\mathrm{MAcA}) \approx 0.6$ are in qualitative agreement with the results of ethylene homopolymerization in the presence of $0.05 \mathrm{~mol} \mathrm{~L}^{-1}$ of the same additive (Figure 1). ${ }^{18}$

A more labile coordination in the catalyst precursor allows for copolymerizations at lower ethylene pressures, and therefore higher incorporations of polar comonomer can be achieved. Motivated by the lower inhibition of ethylene polymerization by MAcA and DMAcA versus DMSO, we investigated the formation of a DMF-coordinated $\left[\left(\mathrm{P}^{\wedge} \mathrm{O}\right) \mathrm{Pd}\right.$ $(\mathrm{Me})]$ complex (Scheme 2). A procedure similar to the synthesis of 1-DMSO starting from 1-TMEDA ${ }^{9 \mathrm{e}}$ (TMEDA = $N, N, N^{\prime}, N^{\prime}$-tetramethyl ethylene diamine), that is, repeated evaporation with excess sulfoxide or amide, respectively, to remove the diamine, was studied. This approach resulted in mixtures of starting material and product (1-DMF) that could not be separated by means of extraction or crystallization. The mixture was soluble in methylene chloride, and two $\mathrm{Pd}-\mathrm{Me}$ resonances could be observed at room temperature. The ${ }^{13} \mathrm{C}$ carbonyl resonance of DMF was only slightly low-field-shifted to $165.35 \mathrm{ppm}$ (162.49 ppm for free DMF under identical conditions), which indicates a rather weak coordination of DMF. A suitable alternative route is therefore the generation of fragment 1 in the absence of other coordinating reagents than DMF. To this end, chloride abstraction from the recently reported dimeric cation bridged anionic complex $[\{(1-\mathrm{Cl})-\mu$ $\left.\mathrm{Na}\}_{2}\right]$ with silver salts was utilized, ${ }^{6 \mathrm{~g}}$ Stirring of $[\{(\mathbf{1}-\mathrm{Cl})-\mu$ $\mathrm{Na}\}_{2}$ ] with 5 equiv of DMF and 0.95 equiv of silver tetrafluoroborate in methylene chloride for one hour in a sealed tube yielded 1-DMF as an off-white powder after filtration, removal of the solvent, and washing with diethyl ether. The proton resonances of the coordinated DMF were low-field-shifted compared to free DMF (3.00 and $2.91 \mathrm{ppm}$ for Me protons and $8.13 \mathrm{ppm}$ for the carbonyl bound proton; Figure S12, Supporting Information). However, 1-DMF is not stable in methylene chloride in the absence of excess DMF and

Scheme 2. Synthesis and Decomposition of 1-DMF

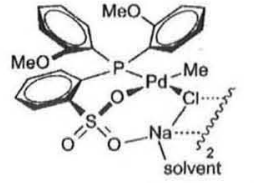

$\left[\{(1-\mathrm{Cl})-\mu-\mathrm{Na}\}_{2}\right]$

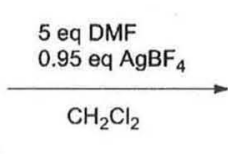

$$
\mathrm{CH}_{2} \mathrm{Cl}_{2}
$$

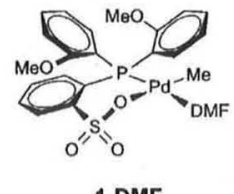

1-DMF

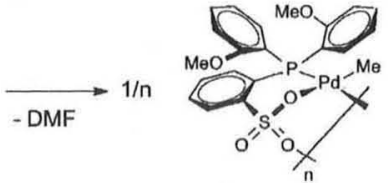

1 n 
decomposed to the multinuclear species $\mathbf{1}_{\mathbf{n}}$, which precipitates during the course of the NMR experiment. Oligomerization of the $\left[\left(\mathrm{P}^{\wedge} \mathrm{O}\right) \mathrm{PdMe}\right]$ fragment via intermolecular coordination of a second oxygen atom of the sulfonate group ${ }^{9 a, e}$ appears to be favored over coordination of DMF.

Insertion of Acrylamides into 1-DMSO. Pseudo-firstorder rate constants for the insertion into the $\mathrm{Pd}-\mathrm{Me}$ bond of 1-DMSO were determined by ${ }^{1} \mathrm{H}$ NMR spectroscopy at $25{ }^{\circ} \mathrm{C}$ (Figure 2, Table 3). ${ }^{19}$ Both acrylamides (NIPAM, DMAA)

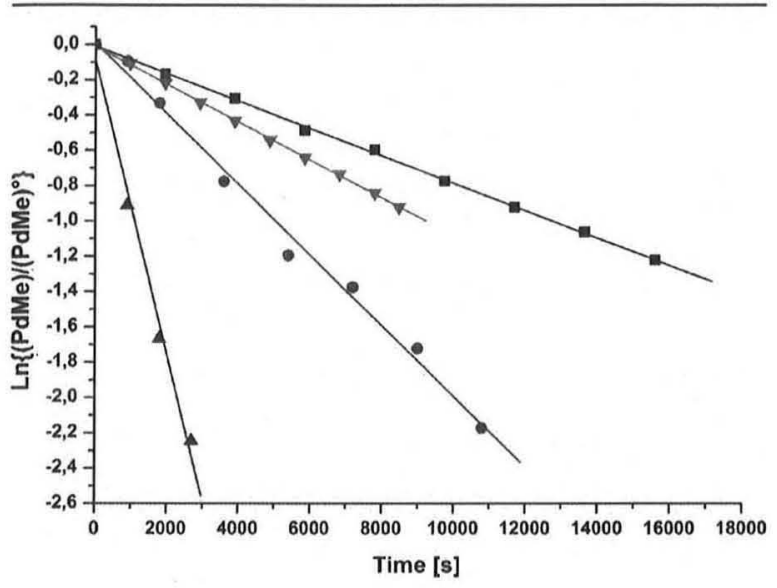

Figure 2. Pseudo-first-order plots of the time-dependent decrease of the Pd-Me resonance of 1-DMSO at $25{ }^{\circ} \mathrm{C}$ for DMAA ( $\square$ ), NIPAM $(\bullet), \operatorname{MA}(\Delta)$, and AcAMEA ( $\nabla)$. [Pd] $=45 \mathrm{mM}$ in $\mathrm{CD}_{2} \mathrm{Cl}_{2} ; 20$ equiv polar monomer.

Table 3. Pseudo-First-Order Rate Constants for the First Insertion into the Pd-Me Bond of 1-DMSO at $25{ }^{\circ} \mathrm{C}$

$\begin{array}{lc}\text { monomer } & k_{\mathrm{obs}}\left[10^{-5} \mathrm{~s}^{-1}\right] \\ \text { MA } & 83.2(58) \\ \text { NIPAM } & 20.0(7) \\ \text { AcAMEA } & 10.7(1) \\ \text { DMAA } & 7.76(9)\end{array}$

inserted considerably slower than MA. Note, however, that the observed rate constants determined also include preinsertion equilibrium competition of DMSO coordination and $\kappa-O$ amide binding vs $\pi$-coordination of the vinyl group. Accordingly, the secondary amide moiety of the acrylate AcAMEA slows down the insertion considerably by comparison to methyl acrylate (Table 3).

Characterization of the reaction mixture obtained after complete insertion of NIPAM into 1-DMSO by ${ }^{1} \mathrm{H}$ NMR spectroscopy was complicated because of multiple isopropyl resonances resulting from several different insertion products. Upon concentration of the methylene chloride solution, a precipitate formed, which could be isolated as a pale yellow solid by filtration and washing with a small amount of methylene chloride. Its low solubility in methanol allowed for ${ }^{1} \mathrm{H}$ and ${ }^{1} \mathrm{H},{ }_{1}^{1} \mathrm{H}-\mathrm{COSY} N M R$ analysis, which clearly revealed the 2,1-insertion product of NIPAM into the $\mathrm{Pd}-\mathrm{Me}$ bond (2) (Figures S13, S14, Supporting Information). Layering a filtrated methanolic solution of 2 with pentane at room temperature afforded single crystals of the methanol adduct suitable for Xray diffraction (Figure 3 ). Both enantiomers with respect to the absolute configuration of the methine carbon $\mathrm{C}(21)$ cocrystal-

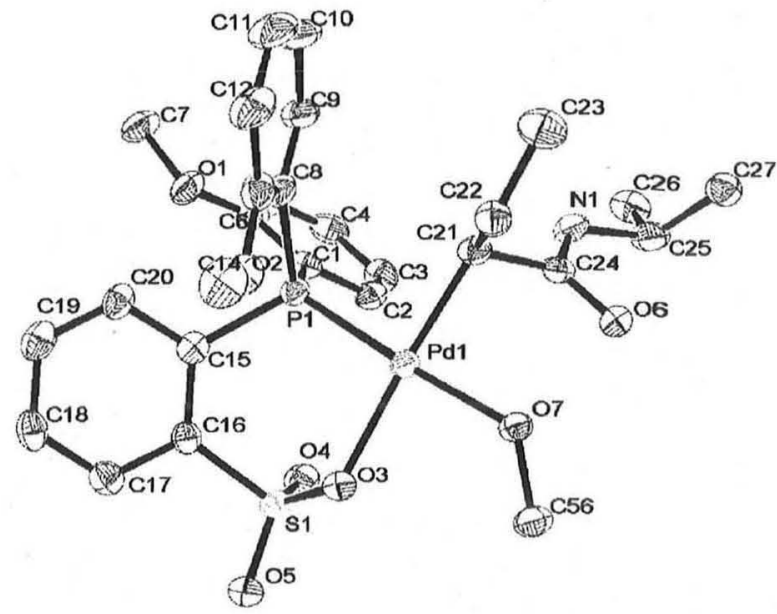

Figure 3. ORTEP plot of the molecular structure of 2-MeOD drawn with $50 \%$ probability ellipsoids. All hydrogen atoms and cocrystallized solvent molecules are omitted for clarity. Selected bond length $(\AA)$ and angles (deg): $\mathrm{Pd}(1)-\mathrm{C}(21)$ 2.059(5), $\mathrm{Pd}(1)-\mathrm{O}(7) 2.116(4), \mathrm{Pd}(1)-$ $\mathrm{O}$ (3) 2.132(4), $\mathrm{Pd}(1)-\mathrm{P}(1)$ 2.201(1), $\mathrm{O}(7)-\mathrm{C}(56) 1.445(6)$ $\mathrm{C}(24)-\mathrm{O}(6) 1.259(6), \mathrm{N}(1)-\mathrm{C}(24) 1.328(7), \mathrm{N}(1)-\mathrm{C}(25)$ 1.472(7), $\mathrm{P}(1)-\mathrm{Pd}(1)-\mathrm{O}(3)$ 94.9(1), O(7) $-\mathrm{Pd}(1)-\mathrm{C}(21) 88.2(2)$ $\mathrm{C}(21)-\mathrm{C}(24)-\mathrm{N}(1) \quad 117.6(5), \mathrm{C}(21)-\mathrm{C}(24)-\mathrm{O}(6) \quad 122.6(5)$ $\mathrm{N}(1)-\mathrm{C}(24)-\mathrm{O}(6) \quad 119.8(5), \mathrm{C}(25)-\mathrm{N}(1)-\mathrm{C}(24) \quad 122.9(5)$ $\mathrm{C}(25)-\mathrm{N}(1)-\mathrm{C}(24)-\mathrm{O}(6)-2.0$.

lized with two free molecules of methanol- $d_{4}$ per asymmetric unit. The Pd center shows a distorted square planar coordination with methanol- $d_{4}$ coordinated trans to the phosphorus atom. While 2-MeOD is poorly soluble in methanol, its solubility is strongly increased by the addition of a small amount of DMSO to the methanol solution. However, immediate $\beta$-hydride elimination was observed in the presence of DMSO. After refluxing for one hour, over $90 \%$ of 2 was converted to $\mathrm{N}$-isopropylcrotoneamide (Figure S13). In the context of the absence of conjugated NIPAM-derived end groups in the ethylene-NIPAM copolymers (vide supra), it is noteworthy that $\beta$-H elimination after 2,1-insertion of NIPAM can be observed in principle.

The insertion products of NIPAM into 1-DMSO were directly observed by electrospray ionization (ESI) mass spectrometry. After a reaction time of $22 \mathrm{~h}$, the products of consecutive NIPAM insertions into the $\mathrm{Pd}-\mathrm{Me}$ bond of 1 DMSO and into the $\mathrm{Pd}$-hydride, formed by $\beta-\mathrm{H}$ elimination, were clearly detected (Figure S15, Supporting Information). For all signals, the found isotope patterns fully agree with expected values.

By contrast, applying an analogous procedure to DMAA, no consecutive insertions were observed by NMR or ESI mass spectrometry (Figure S16, Supporting Information). A mixture of the 2,1- and 1,2-insertion products was observed by NMR after stirring 1-DMSO with 20 equiv of DMAA for $18 \mathrm{~h}$ at 25 ${ }^{\circ} \mathrm{C}$. However, the isolated products were contaminated with homopolymer of DMAA, formed by free-radical polymerization, and small amounts of insertion products into $\mathrm{Pd}-$ hydride species, formed after $\beta$-H elimination. Clean DMAA insertion products in a 4:1 ratio of 2,1- and 1,2-insertion were obtained by chloride abstraction from $\left[\{(1-\mathrm{Cl})-\mu-\mathrm{Na}\}_{2}\right]$ with silver tetrafluoroborate (Scheme 3 ). The complexes were fully characterized by one- and two-dimensional NMR techniques 
Scheme 3. Synthesis of Dimethyl Acrylamide Insertion Products 3,4
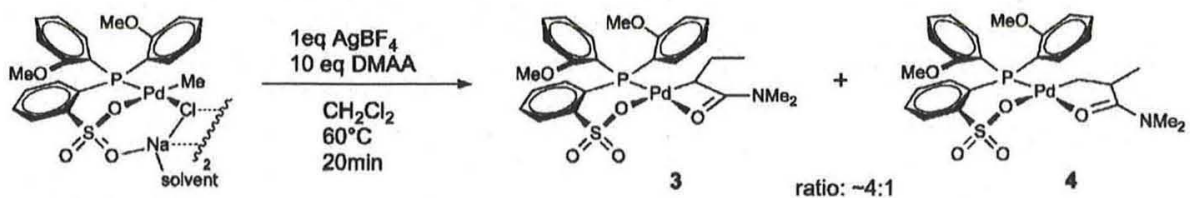

$\left[\{(1-\mathrm{Cl})-\mu-\mathrm{Na}\}_{2}\right]$

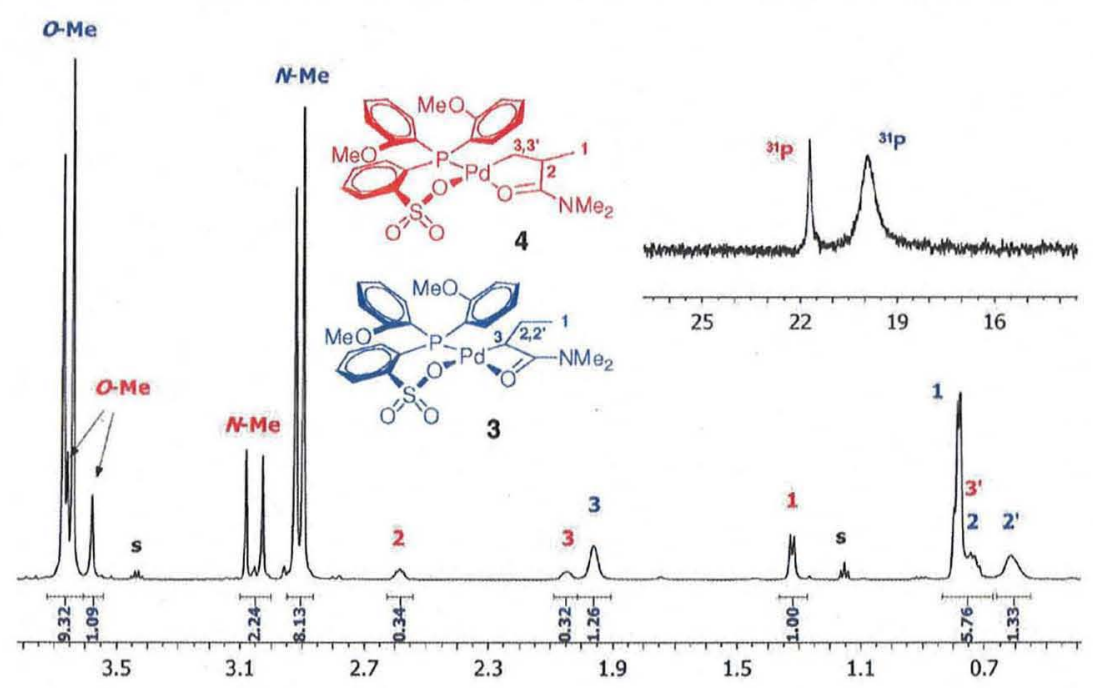

Figure 4. Aliphatic region of ${ }^{1} \mathrm{H}$ NMR spectra of dimethyl acrylamide insertion products 3,4 (formed in a $4: 1$ ratio) in $\mathrm{CD}_{2} \mathrm{Cl}_{2}$ at $25^{\circ} \mathrm{C}$. S: $\mathrm{Residual}$ $\mathrm{Et}_{2} \mathrm{O}$ resonances. Inset: Close up of ${ }^{31} \mathrm{P}$ NMR spectra of 3,4 under identical conditions.

(Figure 4). The ethyl $\mathrm{CH}_{3}$ protons of 3 appear as a triplet at $0.78 \mathrm{ppm}$, whereas the methyl protons of 4 show a doublet splitting at $1.32 \mathrm{ppm}$. Remarkably, the resonances of the diastereotopic methylene protons 3 and 3' in 4 differ by more than $1 \mathrm{ppm}$. The ${ }^{13} \mathrm{C}$ carbonyl resonances are significantly lowfield-shifted to $184.58 \mathrm{ppm}$ for the 2,1 -insertion product 3 and $187.30 \mathrm{ppm}$ for the 1,2 -insertion product 4 , indicating a chelate structure of the complexes, in which the amide group coordinates to the fourth coordination site of the palladium center. ${ }^{20}$ Also, the wavenumber of the carbonyl stretching band of 3,4 is decreased from $1634 \mathrm{~cm}^{-1}$ in free DMAcA to 1584 and $1573 \mathrm{~cm}^{-1}$ in the insertion products (Figure S21, Supporting Information). According to the Cambridge Structure Database, $\kappa$-O-coordination has been observed exclusively in $\mathrm{Pd}(\mathrm{II})$ amide complexes. ${ }^{21}$ Thus, a similar $\kappa$-O-coordination appears likely in 3,4. Noteworthy, the same low-field-shifted carbonyl resonances indicating chelate formation were observed in the (contaminated) insertion products starting from 1-DMSO. In contrast, single insertion of MA results in the formation of the 2,1-insertion product $\left[\left(\mathrm{P}^{\wedge} \mathrm{O}\right) \mathrm{Pd}\left\{\mathrm{CH}\left(\mathrm{CH}_{2} \mathrm{CH}_{3}\right) \mathrm{C}(\mathrm{O}) \mathrm{OMe}\right\}\right.$ (DMSO)] exclusively, in which DMSO coordinates to the Pd center rather than the chelating coordination of the ester moiety in the alkyl fragment. This different behavior relates to the above conclusions on coordination strength of amide moieties, as derived from the extent of inhibition of polymerization (Figure 1).

Reactivity of Dimethyl Acrylamide Insertion Products. Further chain growth requires $\pi$-coordination of olefinic monomer to the Pd center and hence opening of the $\kappa$-Ocoordinated chelate in $\mathbf{3 , 4}$. To this end, the coordination behavior of the monomers and other relevant ligands to the presumed catalyst resting state was investigated. Note that an opening of a chelate by coordination of an incoming ligand will be favored at low temperature because of the unfavorable entropic contribution.

Coordination of ethylene (10 equiv in solution) to 3,4 was not observed even at $-80^{\circ} \mathrm{C}$ by ${ }^{1} \mathrm{H}$ NMR. However, 3,4 are precursors to highly active ethylene polymerization catalysts even at a low ethylene pressure of 2.5 bar (Table 4). Activation

Table 4. Ethylene Homopolymerizations with 3,4 as a Catalyst Precursor ${ }^{a}$

$\begin{array}{cccc}\text { entry } & \mathrm{P}[\mathrm{bar}] & \text { polymer yield }[\mathrm{g}] & \text { average } \mathrm{TOF}^{b}\left[10^{4} \mathrm{~h}^{-1}\right] \\ 1 & 2.5 & 1.63 & 4.7 \\ 2 & 5.0 & 3.19 & 9.1 \\ 3 & 7.5 & 4.07 & 11.6\end{array}$

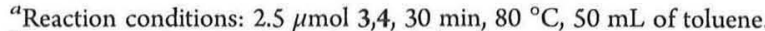
${ }^{b}$ TOF in mol(ethylene) mol(catalyst) ${ }^{-1} \mathrm{~h}^{-1}$.

for polymerization requires coordination and insertion of ethylene, but after a few insertions have occurred, the active species will no longer be prone to chelating coordination of the amide end group because of an entropic disfavoring of large ring chelates. Thus, even if chelate opening by ethylene binding to 3,4 is unfavorable, the latter can be converted to the active species eventually. Polymerization activities are little dependent on ethylene concentration at pressures above 5 atm. Accordingly, at $10 \mathrm{~atm}$, activities are similar to polymerizations with the labile-coordinated 1-DMSO as a catalyst precursor. 
Scheme 4. Reactivity of 3,4 toward Triphenylphosphine

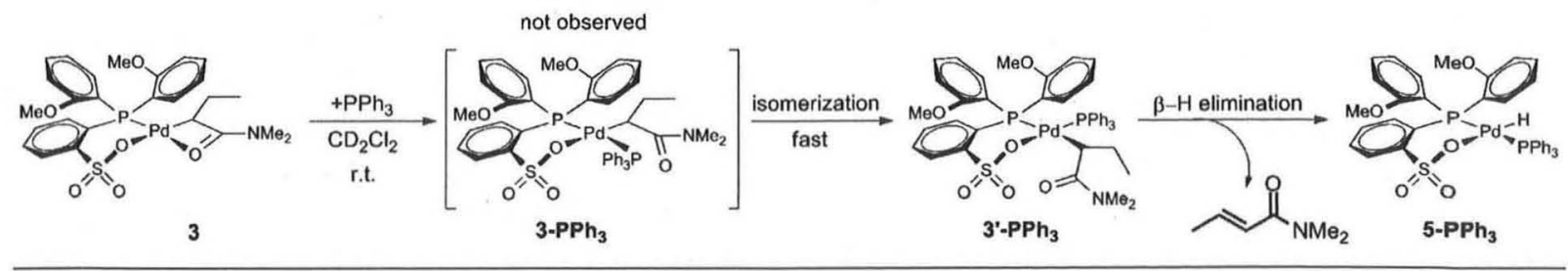

No coordination of DMAA or DMSO, respectively, was observed in the presence of up to 20 equiv at room temperature (Figures S22-1 to -3 , Supporting Information). Both ${ }^{13} \mathrm{C}$ carbonyl resonances of 3,4 remained unaltered. However, small amounts of $N, N$-dimethylcrotoneamide (DMCA), formed by $\beta$ $\mathrm{H}$ elimination from the 2,1-insertion products, were found after $24 \mathrm{~h}$. By comparison, 3,4 is virtually stable over this period of time in methylene chloride solution in the absence of additional reagents. The four-membered chelate of 3 was readily opened in the presence of equimolar amounts of $\mathrm{PPh}_{3}$ and undergoes rapid $\beta$-H elimination (Scheme 4 ). The two ${ }^{31} \mathrm{P}$ resonances of the opened chelate $3^{\prime}-\mathbf{P P h}_{3}$ show a doublet splitting with ${ }^{2} J_{\mathrm{PP} \text {, cis }}$ $=39 \mathrm{~Hz}$. No opened chelate with a trans coordination of the phosphorus atoms (3-PPh $\mathbf{P h}_{3}$ was observed, assumingly because of the trans-effect of the phosphines. The organic product of $\beta$ $\mathrm{H}$ elimination (DMCA) as well as the resulting metal hydride complex $\left(5-\mathbf{P P h}_{3}\right)$ appear in ${ }^{1} \mathrm{H}$ and ${ }^{31} \mathrm{P}$ NMR spectra (Figures S23 and S24, Supporting Information). By contrast, the fivemembered chelate 4 was stable under these conditions even with an excess of $\mathrm{PPh}_{3}$.

The weaker $\sigma$-donor pyridine coordinates to 3 in an observable equilibrium at room temperature, whereas 4 retained its chelated structure as expected from the aforementioned studies. About 2 equiv of pyridine were required to completely form the opened chelate 3-PYR. 3PYR is relatively stable toward $\beta-\mathrm{H}$ elimination in the presence of excess pyridine. After $24 \mathrm{~h}$, only trace amounts of 5-PYR and DMCA were observed along with the isomerized complex 3'PYR (for numbering $\mathrm{cf}$. Scheme 4). By comparison to pyridine, 2,6-lutidine is believed to possess a weaker coordination strength due to steric hindrance. Both opened chelate 3-LUT and 3 can be observed simultaneously in the presence of 2 equiv of 2,6-lutidine at temperatures between 273 and $298 \mathrm{~K}$. On the basis of the ratio of 3 and 3 -LUT obtained from ${ }^{31} \mathrm{P}$ NMR peak areas, the equilibrium constants $K(T)=$ [3-LUT]/ $([3]+[2,6$-lutidine $])$ were calculated. Values for the reaction enthalpy $\Delta H^{\circ}=-41.8(10.5) \mathrm{kJ} \mathrm{mol}^{-1}$ and entropy $\Delta S^{\circ}=$ -115 (37) $\mathrm{J} \mathrm{mol}^{-1} \mathrm{~K}^{-1}$ were obtained by a Van't Hoff plot (Figure S25, Supporting Information). Such a negative enthalpy and unfavorable entropy are generally expected for chelate opening reactions, and the values found are in the same range as reported for similar chelate opening reactions with esterderived five- and six-membered chelates in cationic $\alpha$-diimine complexes. $^{3 \mathrm{~b}, 22,23}$ Extrapolation of the thermodynamic data to typical polymerization conditions with $[2,6$-lutidine $]=1 \mathrm{~mol}$ $\mathrm{L}^{-1}$ yields $K(358 \mathrm{~K}) \approx 1.5$. Considering the higher coordination strength of 2,6-lutidine in comparison to DMAA and ethylene (with typical concentrations of both monomers being on the order of a mol L $\mathrm{L}^{-1}$ in polymerizations), it can be concluded that chelate species formed after an amide insertion will be relevant species in copolymerizations and retard polymerization.

\section{SUMMARY AND CONCLUSIONS}

These combined comprehensive experimental studies of polymerization and stoichiometric insertion reactions reveal fundamental features of insertion polymerization of amides. Other than the somewhat electron-poorer carbonyl group of acrylates, free amides coordinate strongly to the catalyst studied, and hereby the polar monomer itself reversibly retards polymerization. However, the catalysts are stable in the presence of amides, and no indication of irreversible deactivation pathways specific to amide monomers was observed. Chelating coordination of amide moieties of polar monomer incorporated in the growing chain also contributes significantly to lower rates of copolymerization vs ethylene homopolymerization. In detail, these chelates appear to be more stable than corresponding ester chelates, and the impact on polymerization rates is slightly more pronounced than for acrylate copolymerizations. Insertion occurs preferentially in a 2,1-fashion, as expected for electron-poor vinyl monomers because of the strong prevalence of electronic factors in the absence of specific bulky substitution patterns of the catalyst. ${ }^{\text {9f }}$ 1,2-Insertion is also clearly observed (ca. 20\%) and occurs to a larger extent than found for acrylates. ${ }^{9 e, 10}$ This is in-line with electronics determining the regioselectivity, which will be higher for the electron-poorer olefin. Net insertion rates into a $\mathrm{Pd}-\mathrm{Me}$ bond of the secondary and tertiary amides studied are ca. 4- to 8-fold lower by comparison to methyl acrylate. Note that these data include the coordination preequilibrium of displacement of DMSO and competitive $\kappa-O$ amide binding vs the required $\pi$-coordination of the vinyl group. Though consecutive insertions of amide monomer in copolymerizations are unlikely because of their limited incorporation, stoichiometric studies reveal that consecutive insertions of the secondary amide $N$-isopropylacrylamide can occur. Chain transfer occurs more rapidly from the insertion product of the polar amide monomer, $\mathrm{Pd}-\mathrm{CH}\left(\mathrm{CONR}_{2}\right)-\mathrm{CH}_{2}-\mathrm{R}$, by comparison to the unsubstituted alkyls from ethylene chain growth, as is evident from end groups observed in the polymers studied in this work and is also supported by observation of $\beta$ hydride elimination in stoichiometric studies.

Overall, the copolymerization is limited most decisively by the combination of retardation of polymerization by reversible blocking of the coordination site by the amide groups of free monomer and a limited insertion rate. This results in an intrinsic trade-off between the amide content of the copolymer and copolymerization productivity. Other than retardation of polymerization by formation of chelates by polar moieties incorporated in the growing polymer chain, this can not be counterbalanced by increasing the monomer concentrations. In a general view of $\mathrm{Pd}(\mathrm{II})$-catalyzed copolymerization of polar vinyl monomers $\mathrm{CH}_{2}=\mathrm{CHX}$, this comprehensive experimental study of amide copolymerization, together with the inhibition studies reported and a recent detailed theoretical study of acrylonitrile copolymerization ${ }^{17}$ and mechanistic study of 
acrylate polymerization, ${ }^{10}$ evolves the criteria for a privileged monomer. While a retardation of polymerization by slower insertion into the $\alpha$-X substituted alkyl formed by incorporation of polar monomer as well as by chelating $\kappa$-X coordination of comonomer-derived repeat units appear to be general phenomena of such copolymerizations, the weak coordination of the ester group of acrylate monomer ultimately is responsible for the accessability of ethylene copolymers with high incorporations of the polar comonomer.

In the context of these considerations, it is notable that to date no specific irreversible deactivation reactions of neutral $\mathrm{Pd}(\mathrm{II})$ polymerization catalysts have been reported for any polar vinyl comonomer, although they likely occur in some cases.

The aforementioned limitations being understood, they should not obscure the fact that this insertion copolymerization provides a useful access to amide-substituted polyethylenes, which is not sensitive to the nature of the amide substitution pattern.

\section{AUTHOR INFORMATION}

\section{Corresponding Author}

stefan.mecking@uni-konstanz.de

\section{ACKNOWLEDGMENTS}

Financial support by the DFG (Me1388/10) is gratefully acknowledged. The authors thank Lars Bolk for GPC, Boris Neuwald for ESI-MS measurements, Anke Friemel for recording VT ${ }^{13} \mathrm{C}$ NMR spectra, and Thomas Rünzi for performing various polymerizations in presence of additives. Support by Inigo Göttker-Schnetmann in the determination of the crystal structure of 2-MeOD is acknowledged.

\section{REFERENCES}

(1) Mülhaupt, R. Macromol. Chem. Phys. 2003, 204, 289-327.

(2) (a) Ittel, S. D.; Johnson, L. K.; Brookhart, M. Chem. Rev. 2000, 100, 1169-1203. (b) Gibson, V. C.; Spitzmesser, S. K. Chem. Rev. 2003, 103, 283-316. (c) Mecking, S. Coord. Chem. Rev. 2000, 203, 325-351. (d) Mecking, S. Angew. Chem., Int. Ed. 2001, 40, 534-540. (e) Guan, Z. Chem.-Eur. J. 2002, 8, 3086-3092. (f) Domski, G. J.; Rose, J. M.; Coates, G. M.; Bolig, A. D.; Brookhart, M. Prog. Polym. Sci. 2007, 32, 30-92. (g) Chen, E. Y.-X. Chem. Rev. 2009, 109, 51575214. (h) Nakamura, A.; Ito, S.; Nozaki, K. Chem. Rev. 2009, 109, 5215-5244.

(3) (a) Johnson, L. K.; Mecking, S.; Brookhart, M. J. Am. Chem. Soc. 1996, 118, 267-268. (b) Mecking, S.; Johnson, L. K.; Wang, L.; Brookhart, M. J. Am. Chem. Soc. 1998, 120, 888-899.

(4) Foley, S. R.; Stockland, R. A.; Shen, H.; Jordan, R. F. J. Am. Chem. Soc. 2003, 125, 4350-4361.

(5) Berkefeld, A.; Mecking, S. Angew. Chem., Int. Ed. 2008, 47, 25382542.

(6) (a) Luo, S.; Vela, J.; Lief, G. R.; Jordan, R. F. J. Am. Chem. Soc. 2007, 129, 8946-8947. (b) Kochi, T.; Noda, S.; Yoshimura, K.; Nozaki, K. J. Am. Chem. Soc. 2007, 129, 8948-8949. (c) Weng, W.; Shen, Z.; Jordan, R. F. J. Am. Chem. Soc. 2007, 129, 15450-15451. (d) Skupov, K. M.; Piche, L.; Claverie, J. P. Macromolecules 2008, 41, 2309-2310. (e) Ito, S.; Munakata, K.; Nakamura, A.; Nozaki, K. J. Am.
Chem. Soc. 2009, 131, 14606-14607. (f) Bouilhac, C.; Rünzi, T.; Mecking, S. Macromolecules 2010, 43, 3589-3590. (g) Rünzi, T. Guironnet, D.; Göttker-Schnetmann, I.; Mecking, S. J. Am. Chem. Soc. 2010, 132, 16623-16630. (h) Rünzi, T.; Fröhlich, D.; Mecking, S. J. Am. Chem. Soc. 2010, 132, 17690-17691. (i) Daigle, J.-C.; Piche, L.; Claverie, J. P. Macromolecules 2011, 44, 1760-1762.

(7) Olefin-CO copolymerizations: (a) Drent, E.; van Dijk, R.; van Ginkel, R.; van Oort, B.; Pugh, R. I. Chem. Commun. 2002, 964-965. (b) Hearley, A. K.; Nowack, R. J.; Rieger, B. Organometallics 2005, 24, 2755-2763. (c) Kochi, T.; Nakamura, A.; Ida, H.; Nozaki, K. J. Am. Chem. Soc. 2007, 129, 7770-7771. (d) Nakamura, A.; Munakata, K. Ito, S.; Kochi, T.; Chung, L. W.; Morokuma, K.; Nozaki, K. J. Am. Chem. Soc. 2011, 133, 6761-6779.

(8) Drent, E.; van Dijk, R. van Ginkel, R.; van Oort, B.; Pugh, R I. Chem. Commun. 2002, 744-745.

(9) (a) Vela, J.; Lief, G. R.; Shen, Z.; Jordan, R. F. Organometallics 2007, 26, 6624-6635. (b) Skupov, K. M.; Marella, P. R.; Simard, M.; Yap, G. P. A; Allen, N.; Conner, D.; Goddall, B. L.; Claverie, J. P. Macromol. Rapid Commun. 2007, 28, 2033-2038. (c) Borkar, S.; Newsham, D. K.; Sen, A. Organometallics 2008, 27, 3331-3334. (d) Noda, S.; Nakamura, A.; Kochi, T.; Chung, L. W.; Morokuma, K.; Nozaki, K. J. Am. Chem. Soc. 2009, 131, 14088-14100. (e) Guironnet, D.; Roesle, P.; Rünzi, T.; Göttker-Schnetmann, I.; Mecking, S. J. Am. Chem. Soc. 2009, 131, 422-423. (f) Wucher, P.; Caporaso, L.; Roesle, P.; Ragone, F.; Cavallo, L.; Mecking, S.; Göttker-Schnetmann, I. Proc. Natl. Acad. Sci. U. S. A. 2011, 108, 8955-8959.

(10) Guironnet, D.; Caporaso, L.; Neuwald, B.; Göttker-Schnetmann, I.; Cavallo, L.; Mecking, S. J. Am. Chem. Soc. 2010, 132, 4418-4426.

(11) Related stoichiometric studies of acrylate insertion in $\mathrm{Pd}(\mathrm{II})$ complexes: (a) Braunstein, P.; Frison, C.; Morise, X. Angew. Chem., Int. Ed. 2000, 39, 2867-2870. (b) Agostinho, M.; Braunstein, P. Chem. Commun. 2007, 58-60.

(12) (a) Marques, M. M.; Fernandes, S.; Correia, S. G.; Ascenso, J. R.; Caroço, S.; Gomes, P. T.; Mano, J.; Pereira, S. G.; Nunes, T.; Dias, A. R.; Rausch, M. D.; Chien, J. C. W. Macromol. Chem. Phys. 2000, 201, 2464-2468. (b) Fernandes, S.; Ascenso, J. R.; Gomes, P. T.; Costa, S. I.; Silva, L. C.; Chien, J. C. W.; Marques, M. M. Polym. Int. 2005, 54, 249-255.

(13) Also cf. Conner, D. M.; Goodall, B. L.; McIntosh, L. H. U.S. Pat. 7524905 B2, 2009 for further polymerizations with these catalysts to ethylene copolymers with $0.5 \mathrm{~mol} \% \mathrm{~N}$-vinylphthalimide incorporation.

(14) The concentrationof ethylene in toluene $\left(85^{\circ} \mathrm{C}\right)$ at 90 and 200 psi is 0.28 and $0.68 \mathrm{~mol} \mathrm{~L}^{-1}$, respectively: Skupov, K. M.; Hobbs, J.; Marella, P.; Conner, D.; Golisz, S.; Goodall, B. L.; Claverie, J. P. Macromolecules 2009, 42, 6953-6963.

(15) Internal olefins were accounted for as ethylene-derived end groups.

(16) The frequencies ofcarbonyl stretching bands of acetamide (AcA), MAcA, and DMAcA decreasewith increasing degree of substitution, indicating a higher negativepartial charge on the oxygen atom: Gerrard, W.; Lappert, M. F.; Pyszora, H.; Wallis, J. W. J. Chem. Soc. 1960, 2144-2151 .However, the overall coordination strength appears to be dominatedby the steric bulk of the $\mathrm{N}$-substituents, which disfavorscoordination, as concluded from the inhibition studies.

(17) Nozaki, K.; Kusumoto, S.; Noda, S.; Kochi, T.; Chung, L. W.; Morokuma, K. J. Am. Chem. Soc. 2010, 132, 16030-16042.

(18) That the trends differ somewhat in detail may be related to the fact that the relative binding studies employ $\mathrm{Pd}-\mathrm{Me}$ species, whereas in polymerization, relative binding in the bulkier Pd-alkyls (alkyl = growing chain) is relevant. Also, although the temperature dependence of an equilibrium $\mathrm{A}+\mathrm{B} \rightleftarrows \mathrm{C}+\mathrm{D}$ should be expected to be limited, the different temperatures of the NMR studies $\left(25^{\circ} \mathrm{C}\right)$ and the polymerization studies $\left(80^{\circ} \mathrm{C}\right)$ can contribute.

(19) Several insertion products were formed in the case of DMAA and NIPAM. The decrease of the Pd-Me resonance was monitored in all cases, and the obtained rate constants represent overall insertion rates. 
(20) Other neutral five-memberedPd(II) amide chelates were reported to have ${ }^{13} \mathrm{C}$ carbonylresonances between 180 and 182 ppm: Dghaym, R. D.; Yaccato, K. J.; Arndtsen, B. A. Organometallics $1998,17,4-6$

(21) For example: (a) Yagyu, T.; Aizawa, S.; Funahashi, S. Bull. Chem. Soc. Jpn. 1998, 71, 619-629. (b) Braunstein, P.; Frison, C.; Morise, X. C. R. Chim. 2002, S, 131-135. (c) Bagchi, V.; Bandyopadhyay, D. Acta Crystallogr., Sect. E: Struct. Rep. Online 2007, 63, 1614-1615. (d) Bedford, R. B.; Hazelwood, S. L.; Limmert, M. E.; Brown, J. M.; Ramdeehul, S.; Cowley, A. R.; Coles, S. J.; Hursthouse, M. B. Organometallics 2003, 22, 1364-1371.

(22) Williams, B. S.; Leatherman, M. D.; White, P. S.; Brookhart, M. J. Am. Chem. Soc. 2005, 127, 5132-5146.

(23) For an analogous neutral phosphinosulfonate complex, surprisingly low absolute values were obtained for the opening of a six-membered chelate with DMSO $\left(\Delta H^{\circ}-3.0(6) \mathrm{kJ} \mathrm{mol}^{-1}\right.$ and $\Delta S^{\circ}$ $-3(2) \mathrm{J} \mathrm{mol}^{-1} \mathrm{~K}^{-1}$ ), which possibly relates to the incoming ligand. ${ }^{10}$ 